\title{
Non-fatal animal related injuries to youth occurring on farms in the United States, 1998
}

\author{
K J Hendricks, N Adekoya
}

\begin{abstract}
Objective-To provide data on the magnitude and patterns of animal related onfarm injuries to youth in the United States.

Data source-A survey of 26000 farm households conducted for the National Institute for Occupational Safety and Health by the United States Department of Agriculture in 1998.

Subjects-Youth younger than 20 years of age.

Results-There were an estimated 6438 animal related on-farm injuries to youth in $1998.70 \%$ occurred to farm residents; $69 \%$ were work related. Males accounted for $64 \%$ and approximately $41 \%$ occurred to those younger than $10 ; 37 \%$ involved horses and $31 \%$ cattle. Most horse related injuries occurred to females and a majority of the cattle related injuries were to males. Additionally, most of the cattle related injuries were work related, while horse related injuries were mainly nonwork.

Conclusions-One out of every five youth injuries occurring on farms in the United States is animal related. These animal related injuries were due to both work and non-work related exposures. The large number of horse and cattle related injuries highlights a need for intervention strategies based on the injury circumstances common to these animals.

(Injury Prevention 2001;7:307-311)
\end{abstract}

Keywords: farm; youth; animals

Farming is widely recognized as a hazardous occupation for persons of all ages. ${ }^{1-3}$ Youth are exposed to farm hazards from a variety of mechanisms, ${ }^{4}$ and unique hazards exist simply by virtue of their living, working, visiting, and playing on the farm. Although the exact number of youth exposed to farming hazards is unknown, available data indicate an average of 104 youth under 20 die on farms annually. ${ }^{5}$ In 1994, the national estimate of lost-time injuries to youth farm workers under the age of 20 was $10173 .{ }^{6}$

Although farm machinery and tractors have been identified as a primary cause of agricultural injuries, ${ }^{78}$ farm animals have also been identified as a major source of injury. ${ }^{9-11}$ Data specific to youth in Wisconsin has shown that for injuries requiring hospital admission, farm animals were the cause of $40 \%{ }^{4}$

The problem of animal related injuries to youth on farms has also been noted beyond the
United States. ${ }^{12-16}$ A study of youth on farms in Australia indicated that $86 \%$ reported working with farm animals. Almost 55\% had experienced an injury, $44 \%$ were caused by a farm animal. In addition, $72 \%$ perceived working with animals as the most dangerous activity on the farm. ${ }^{13}$

Horses have been identified as a major cause of these injuries. ${ }^{14-17}$ Horses are found on many different types of farms and are used for both recreation and farm work, which may increase their exposure and injury risk. ${ }^{17} \mathrm{~A}$ study in Great Britain found that horseback riding results in more injuries per hour than motorcycle riding. ${ }^{14}$ In the United States, research using the National Electronic Injury Surveillance System, a hospital emergency department surveillance system, estimated 7500 farm injuries to youth resulting from horseback riding on farms between 1990 and 1993. ${ }^{5}$ Other studies have shown young females to have a horse related injury rate three times higher than males, which differs from other types of on-farm injuries where males generally experience more injuries than females. ${ }^{13}{ }^{14}$ Falls are the predominant type of injury for those engaged in riding, while being kicked or stepped on is the most frequent injury for those on the ground who are in close proximity to the horse. ${ }^{15} 16$ Falls from horses result almost exclusively in head and upper extremity injuries, with studies indicating that fractures, lacerations, and contusions are the most frequent type of outcomes associated with these injuries. ${ }^{18}$

Working with cattle was identified by youth (10-14 years) living on farms in Australia as more than twice as hazardous as horses. ${ }^{13}$ Studies conducted in Vermont and Wisconsin found that a large proportion of injuries on farms involved contact with cattle. ${ }^{10} 11$ In a study of two rural Vermont hospitals, more than one third of all injuries that occurred on dairy farms involved contact with cattle, with $5 \%$ occurring to youth under $15 .{ }^{10}$ Cattle related injuries were most commonly the result of being kicked or pushed by the cattle. ${ }^{10}{ }^{19}$ The extremities have been identified as the most frequent site of injury. ${ }^{11}$

The National Committee for Childhood Agricultural Injury Prevention has reported that accurate injury statistics are needed to detect trends in types, frequency, and severity of childhood agricultural injuries. ${ }^{20}$ Previous studies on animal related injuries among youth on farms have generally been limited to individual states or local areas, and have not examined the problem on a national level. In part to help address this gap in national injury 
data, a national farm operators' survey on youth farm injuries was conducted. This analysis focused on all on-farm animal related injuries to youth less than 20 years of age identified in the survey.

\section{Methods}

In February, 1999 the National Institute for Occupational Safety and Health, through an interagency agreement with the United States Department of Agriculture, sponsored a regionally stratified telephone survey of 26000 farm households across the United States on farm related injuries to youth less than 20 years of age that occurred during 1998. Sampling was based on Bureau of the Census geographic regions. For this study, an injury was defined as any event occurring on the farm operation (farm property) that required at least four hours of restricted activity or required the individual to seek professional medical attention. A farm was defined as any operation that had at least $\$ 1000$ in gross receipts in a calendar year. Information was collected on both work and non-work injuries occurring to youth who were either living on the farm, visiting the farm, or hired directly to work on the farm and excluded injuries to contract laborers. A work related injury was defined as any injury that occurred while performing activities that had a direct impact on the farming operation as a business, regardless of whether the activity was performed for pay.

General injury information, such as source, event, nature, body part, work relatedness of the injury, and an injury narrative were collected for up to four injuries per farm. Source and event were coded per the Occupational Injury and Illness Classification scheme. ${ }^{21}$ For farms with more than four injuries in 1998, respondents were asked for information on the four most recent injuries. More detailed questions, such as helmet use, were asked for horse related injuries. Demographic information was also collected for the farm household and for any youth hired to work on the farm. Since demographic information was available only for household youth and hired workers, estimates of injury rates were calculated excluding any injuries to visitors.

On-farm animal related injuries were selected from the data by selecting respondents who answered positively to the questions asking if a horse or any other livestock or animal was involved. In some instances an injury could involve several animals such as a person being injured while riding a horse and herding cattle. In these cases, the animal that was the primary source of injury was selected.

Sampling weights were calculated based on the total number of farms responding by geographical region (that is, stratum) and the number of farms reported in the 1997 Census of Agriculture for each region. All estimates and variances for both the injury and the demographic data were obtained using the unbiased estimators for a stratified simple random sample. ${ }^{22}$ Estimates and $95 \%$ confidence intervals are presented where the standard
Table 1 Estimated animal related on-farm injuries to youth less than 20, United States, 1998

\begin{tabular}{|c|c|c|}
\hline & $\begin{array}{l}\text { Youth injuries } \\
(\%)\end{array}$ & $\begin{array}{l}95 \% \text { Confidence } \\
\text { interval }\end{array}$ \\
\hline All animal injuries & 6438 & 4892 to 7984 \\
\hline \multicolumn{3}{|l|}{ Sex } \\
\hline Male & $2958(46)$ & 1908 to 4009 \\
\hline Female & $1635(25)$ & 910 to 2360 \\
\hline Unknown & $1845(29)$ & - \\
\hline \multicolumn{3}{|l|}{ Age group } \\
\hline$<10$ & $2658(41)$ & 1641 to 3675 \\
\hline $10-15$ & $1864(29)$ & 1062 to 2666 \\
\hline $16-19$ & $1917(30)$ & 1078 to 2756 \\
\hline \multicolumn{3}{|l|}{ Work status } \\
\hline Work & $4427(69)$ & 3131 to 5723 \\
\hline Non-work & $2011(31)$ & 1172 to 2850 \\
\hline \multicolumn{3}{|l|}{ Type of injury } \\
\hline Scrape/abrasion & $1670(26)$ & 849 to 2491 \\
\hline Cut/laceration & $1158(18)$ & 493 to 1821 \\
\hline Broken bone/fracture & $1057(17)$ & 432 to 1682 \\
\hline Bruise/contusion & $992(15)$ & 469 to 1515 \\
\hline Other & $1561(24)$ & 820 to 2302 \\
\hline \multicolumn{3}{|l|}{ Residency } \\
\hline Farm resident & $4484(70)$ & 3192 to 5776 \\
\hline Non-resident & $1954(30)$ & 1107 to 2801 \\
\hline \multicolumn{3}{|l|}{ Animal } \\
\hline Horse & $2382(37)$ & 1478 to 3286 \\
\hline Cattle & $1987(31)$ & 1119 to 2855 \\
\hline
\end{tabular}

error does not exceed $33 \%$ of the estimate. Age groups presented in tables are not consistent in order to meet the above standard for reporting.

\section{Results}

During 1998, there were an estimated 32808 (95\% confidence interval (CI) 28416 to 37200 ) injuries to youth that occurred on farms (injury rate $=1.7 / 100$ farms). Of these on-farm injuries, 6438 were animal related. Forty six per cent (2958) of the animal related injuries occurred to males, and $25 \%$ to females (1635; table 1). In approximately 1800 cases, sex was not reported. An estimated 4484 $(70 \%)$ injuries occurred to youth who were living on the farm, and 1954 (30\%) occurred to hired workers or visitors to the farm.

Table 1 also shows the distribution of animal related farm injuries by age group. Over $40 \%$ (2658) occurred to youth under 10, 1864 (29\%) injuries involved those age 10-15, and $1917(30 \%)$ to youth $16-19$. Sixty nine per cent (4427) occurred while the youth was completing work on the farm, with 2011 injuries resulting from non-work activities.

The types of on-farm animal related injuries that most frequently occurred were scrapes and abrasions $(26 \%)$, cuts and lacerations (18\%), fractures $(17 \%)$, and contusions (15\%; table 1). The body parts most frequently injured were the head/skull $(1580 ; 95 \%$ CI 798 to 2362 ) and the hand/wrist/fingers (1408; 95\% CI 687 to 2129). A majority involved either horses $(37 \%)$ or cattle $(31 \%)$. In the remaining cases $(2069 ; 95 \%$ CI 1160 to 2978) either some other animal (for example, pig, dog, etc) was involved or the animal was not specified.

\section{HORSES}

In an estimated 2382 of the on-farm animal related injuries, a horse was the primary source of injury. Females incurred the most horse related injuries (46\%). Approximately $38 \%$ of the horse related injuries involved those under 10 (table 2). In 1466 of the injuries, the youth 
Table 2 Estimated horse related on-farm injuries to youth less than 20 by sex and age, United States, 1998

\begin{tabular}{|c|c|c|}
\hline & $\begin{array}{l}\text { Youth injuries } \\
(\%)\end{array}$ & $\begin{array}{l}\text { 95\% Confidence } \\
\text { interval }\end{array}$ \\
\hline Horse related injuries & 2382 & 1478 to 3286 \\
\hline \multicolumn{3}{|l|}{ Sex } \\
\hline Male & $950(40)$ & 372 to 1528 \\
\hline Female & $1105(46)$ & 511 to 1699 \\
\hline Unknown & $327(14)$ & - \\
\hline \multicolumn{3}{|l|}{ Age group } \\
\hline$<10$ & 899 (38) & 336 to 1462 \\
\hline $10-19$ & $1484(62)$ & 778 to 2190 \\
\hline \multicolumn{3}{|l|}{ Residency } \\
\hline Farm resident & $1466(62)$ & 774 to 2158 \\
\hline Non-resident & $916(38)$ & 344 to 1488 \\
\hline \multicolumn{3}{|l|}{ Work status } \\
\hline Work & $822(35)$ & 295 to 1349 \\
\hline Non-work & $1560(65)$ & 833 to 2287 \\
\hline
\end{tabular}

Table 3 Estimated animal related injury rates for household and hired youth less than 20 injured on farms, United States, 1998

\begin{tabular}{|c|c|c|}
\hline \multirow[b]{2}{*}{ Animal injury, gender } & \multicolumn{2}{|c|}{ Household and hired youth only } \\
\hline & $\begin{array}{l}\text { No of injuries } \\
\text { (SE) }\end{array}$ & $\begin{array}{l}\text { Injury rate per } \\
100 \text { youth (SE) }\end{array}$ \\
\hline All animal injuries & $6228(783)$ & $0.32(0.04)$ \\
\hline Male & $2844(533)$ & $0.23(0.04)$ \\
\hline Female & 1575 (369) & $0.23(0.05)$ \\
\hline Horse related injuries & $2172(452)$ & $0.11(0.02)$ \\
\hline Male & $837(289)$ & $0.07(0.02)$ \\
\hline Female & $1045(301)$ & $0.15(0.04)$ \\
\hline Cattle related injuries & $1987(443)$ & $0.10(0.02)$ \\
\hline Male & $1459(385)$ & $0.12(0.03)$ \\
\hline Female & $384(180)$ & $0.06(0.03)$ \\
\hline
\end{tabular}

$\mathrm{SE}=$ standard error.

was living on the farm at the time. In an estimated $1560(65 \%)$ cases the injury occurred while the youth was involved in non-work activities. Table 3 shows the injury rate for horse related injuries for household and hired females is more than twice the rate for males.

In 1505 cases (95\% CI 815 to 2195 ), the horse related injuries occurred while the youth was riding the horse, with 969 (95\% CI 414 to 1524) resulting from being thrown from the horse. Three quarters (1132; 95\% CI 528 to 1736) of the youth who were injured while riding were not wearing a protective helmet. A significant difference was found for helmet use by $\operatorname{sex}\left(\chi^{2}=43.185, \mathrm{p}<0.001\right)$ with females wearing helmets $16 \%$ of the time compared with $9 \%$ for males.

CATTLE

Cattle were the primary source of injury in an estimated 1987 of the on-farm animal related injuries during 1998. Approximately 73\% (1459) involved males. Almost half of the cattle related injuries (986) occurred to youth under 16. In 1279 cases (95\% CI 591 to 1967), the injured youth lived on the farm, with all of the cattle related injuries occurring to either household members or youth hired to work on the farm. An estimated 1843 (95\% CI 1010 to 2676) occurred while completing work. Moving or herding cattle was the task most commonly being performed at the time of injury $(803 ; 95 \%$ CI 242 to 1364$)$.

\section{Discussion}

Information about the incidence and circumstances of animal related injuries among youth
Key points

- One out of every five on-farm injuries to youth in the United States is animal related.

- Horses or cattle were involved in more than two thirds of the injuries.

- Females have a horse related injury rate more than twice the rate of males.

- Over $40 \%$ of the on-farm animal related injuries occurred to youth less than 10 .

- $70 \%$ of the injuries occurred to youth who were living on the farm.

- $69 \%$ of injuries occurred while the youth was performing work on the farm.

under 20 on farms is needed to target and develop effective injury prevention strategies. This study estimates that one out of every five farm injuries to youth in the United States is animal related. Many of these injuries involved children under 10, and a large number of youth were injured while working on the farm.

The high proportion of animal related injuries among youth living on farms indicates that animals are a hazard to this population. Previous studies have identified horses and cattle as the leading cause of animal related farm injuries. ${ }^{43}$ These two animals were also the leading cause of injuries reported in this study. An estimated 1260000 youth less than 20 years live on farms in the United States. ${ }^{24}$

The age distribution of on-farm animal related injuries shows youth less than 10 contributing slightly more than $40 \%$ of the cases. The relatively high proportion of injuries to these youth may reflect their early introduction to farm work, and a lack of experience and knowledge of the hazards related to large farm animals. One study found that $77 \%$ of youth 4 through 7 years of age who live on farms participated in work activities in some manner, with feeding livestock as the leading activity. ${ }^{25}$

Sex differences for horse related injuries reported in this study are consistent with what has been previously reported. ${ }^{14}{ }^{18}$ Although the total animal related injury rates are similar for both sexes, horse related injury rates for females are higher than males. We were unable to determine if riders had taken safety classes, engaged in risky behaviors, or if there were other contributing factors.

Herding or moving cattle was responsible for most of the cattle related injuries in this study which included all farms with cattle. The relative risk of injuries from cattle for males to females was 2.0. Previous research on cattle injuries has found handling cattle to be a contributor to injuries. ${ }^{89}$ The identification of hazardous work activities is essential for those who assign tasks and supervise youth at work. Supervisors should take into consideration not only age, but also a youth's physical and mental abilities when deciding which jobs a youth can safely accomplish.

The on-farm animal related injuries reported in this research are both work and nonwork related incidents, although a higher proportion of the injuries were work related. 
Many reasons have been cited in the literature as possible injury risk factors for youth. The lack of childcare arrangements and the farm location serving as both a place of residence and work have been cited as major exposure factors. ${ }^{5}$ Increased activity and curiosity before the development of mature decision making among youth could also be a factor. ${ }^{4}$

Child labor laws for agriculture, set forth under the Fair Labor Standards Act, apply to youth under 16 hired to work on farms. Youth employed by their parents or a guardian on a farm owned or operated by their parent or guardian are exempt from these regulations. ${ }^{26}$ Among the hazardous orders for agriculture is one that prohibits youth under 16 from working on a farm in a yard, pen, or stall occupied by: (1) a bull, boar, or stud horse maintained for breeding or (2) a sow with suckling pigs, or a cow with a newborn calf. These regulations would not apply to $70 \%$ of injuries reported in this study since the youth were injured on their family's farm.

Several non-regulatory approaches have been recommended to prevent childhood work and non-work related injuries on farms. ${ }^{27}$ The North American Guidelines for Childhood Agricultural Tasks, which were recently established by the National Children's Center for Rural and Agricultural Health and Safety, present guidelines for parents to follow in assigning tasks to children age $7-16$ based on their development abilities. ${ }^{28}$ Ten of the 62 guidelines deal with animal care and handling. The guidelines were developed by consensus of different stakeholder groups, and may or may not be supported by scientific data.

In a substantial number of the horse related injuries, the injured youth were not wearing any protective headgear. This is particular troubling when paired with the fact that $29 \%$ of the horse related injuries in this study occurred to the face and head. Previous research has shown that without a protective helmet the injury severity and mortality associated with an individual being thrown from a horse is comparable to being struck by a car. ${ }^{29}$ An educational campaign, similar to that used for bicycle helmets, could help to increase the use of protective headgear for horseback riding and possibly prevent many injuries.

\section{LIMITATIONS}

Limitations for this study are minimal. Although the recall period of an injury was only one year, and information was requested for only the most serious injuries, the potential for recall bias still exists. A study of the effect of recall bias found a $32 \%$ decrease in injury reports for surveys based on a 12 month recall period. ${ }^{30}$ However, injuries that resulted in lost workdays (more severe) had a lower rate of under-reporting $(22.5 \%)$ than injuries that did not result in lost work days $(44.6 \%)$. This study collected information on injuries that required at least four hours of restricted activity or required medical attention. Therefore, the number of injuries reported should be considered a conservative estimate. Youth farm workers hired by a contractor, although an important part of the agricultural work force, were excluded from this study. This exclusion was made based on the belief that contract laborers would be more likely to report injuries to the contractor and not the farm operator. Lastly, due to the small number of injuries in certain categories (for example, cattle related injuries to females, work status by age group, farm type, and regional breakdowns), the standard errors exceed an acceptable level and were not reportable.

\section{Implications for prevention}

Safety messages targeted at youth living on farms holds the possibility of decreasing the number of animal related on-farm injuries. Farm families are key players in any farm safety prevention initiative. ${ }^{31}$ Efforts to reduce or eliminate on-farm animal related injuries should be directed to farm residents and operators who hire youth. Efforts should be made to educate farm youth about the many dangers presented by farm animals. In addition to educational efforts, structural modification of barns to limit animal interaction, isolation of dangerous animals, adequate supervision of youth, and wearing protective gear in recreational and work activities are a few of the prevention strategies that may reduce these injuries.

1 Bell CA, Stout NA, Bender TR, et al. Fatal occupational injuries in the United States, 1980 through 1985. FAMA 1990;263:3047-50.

2 Windau J, Sygnatur E, Toscano G. Profile of work injuries incurred by young workers. Fatal workplace injuries in 1997: a collection of data and analysis. Washington, DC: US Department of Labor, Bureau of labor Statistics, 1999. (Report 934.)

3 Hoskin AF, Miller TA. Farm accident surveys: a 21-state summary with emphasis on animal-related injuries. fournal summary with emphasis on anim
of Safety Research 1979;11:2-13.

4 Cogbill TH, Busch HM, Stiers GR. Farm accidents in children. Pediatrics 1985;76:562-6.

5 Rivara FP. Fatal and non-fatal farm injuries to children and adolescents in the United States, 1990-3. Inj Prev 1997;3: $190-4$.

6 Myers JR. Injuries among farm workers in the United States, 1994. Cincinnati, OH: US Department of Health and Human Services, National Institute for Occupational Safety and Health, 1998. NIOSH Publication No 98-153.)

7 Etherton JR, Myers JR, Jensen RC, et al. Agricultural machine-related deaths. Am f Public Health 1991;81:7668.

8 Brison J, Pickett W. Fatal farm injuries in Ontario, 1984 through 1992. Can f Public Health 1995;86:246-8.

9 Boyle D, Gerberich SG, Gibson RW, et al. Injury from dairy cattle activities. Epidemiology 1997;8:37-41.

10 Waller JA. Injuries to farmers and farm families in a dairy state. $\mathcal{F}$ Occup Med 1992;34:414-21

11 Layde PM, Nordstrom DL, Stueland D, et al. Animalrelated occupational injuries in farm residents. Fournal of Agricultural Safety and Health 1996;2:27-37.

12 Doyle Y, Conroy R. A one year survey of accidents in Irish farms and their medical outcome. Fournal of Occupational Accidents 1988;10:199-208.

13 Chapman P, Spinks D. Recognition of farm hazards by children engaged in farming activities. Fournal of Occupational

14 Chitnavis JP, Gibbons CL, Hirigoyen M, et al. Accidents with horses: what has changed in 20 years? Injury: International fournal of the Care of the Injured 1996;27:1035 .

15 Aronson H, Tough SC. Horse-related fatalities in the province of Alberta, 1975-1990. Am f Forensic Med Pathol 1993;14:28-30

16 Edixhoven P, Sinha SC, Dandy DJ. Horse injuries. Injury: The British fournal of Accident Surgery 1981;12:279-82.

17 Reed DB, Novak SP, Heath R. Farm youth and horserelated injuries: a case for safety helmets. Fournal of Agromedicine 1998;5:45-57.

18 Centers for Disease Control. Current trends associated with horse-back riding-US, 1987 and 1988. MMWR Morb Mortal Wkly Rep 1990;39:329-32.

19 Casey GM, Grant AM, Roerig DS, et al. Farm worker injuries associated with cows: New York state 1991-1996. American Association of Occupational Health Nurses fournal 1997;45:446-50. 
20 National Committee for Childhood Agricultural Injury Prevention. Children and agriculture: opportunities for safety and health. Marshfield, WI: Marshfield Clinic, 1996.

21 Bureau of Labor Statistics. Occupational injury and illness classification manual. Washington, DC: US Department of Labor, Bureau of Labor Statistics, 1992.

22 Cochran WG. Sampling techniques. 3rd Ed. New York, NY: J Wiley, 1977.

23 Cogbill TH, Steenlace E, Landercaster J, et al. Death and disability from agricultural injuries in Wisconsin: a 12-year experience with 739 patients. F Trauma 1991;31:1632-7.

24 National Institute for Occupational Safety and Health. Childhood Agricultural Injuries Survey, 1998 (research file). Unpublished analysis by the NIOSH Division of Safety Research.

25 Houghton RM, Wilson AG. The prevention of injury among farmers, farm workers, and their families: a programme for development of interventions for rural communities-farm survey findings. Dunedin, New Zealand: University of Otago Consulting Group, 1994.
26 Department of Labor. Child labor requirements. Agriculture under the fair labor standard act. (Child Labor Bulletin No 102.) Washington, DC: US Department of Labor, Employment Standards Administration, Wage and Hour Division, 1990.

27 Castillo DN, Adekoya N, Myers JR. Fatal work-related injuries in the agriculture production and services sectors among youth in the United States, 1992-96. Fournal of Agromedicine 1999;6:27-41.

28 National Children's Center for Rural and Agricultural Health and Safety. North American guidelines for children's agricultural tasks. Marshfield, WI: NCCRAHS, 1999.

29 Bond GR, Cristoph RA, Rodgers BM. Pediatric equestrian injuries: assessing the impact of helmet use. Pediatrics 1995;94:487-9.

30 Landen DD, Hendricks S. Effect of recall on reporting of at-work injuries. Public Health Rep 1995;110:350-4.

31 Burgus S. Family farm seminars. Fournal of Agromedicine 1997;4:335-41.

\section{Editorial Board member: brief biography}

ANNE TURSZ

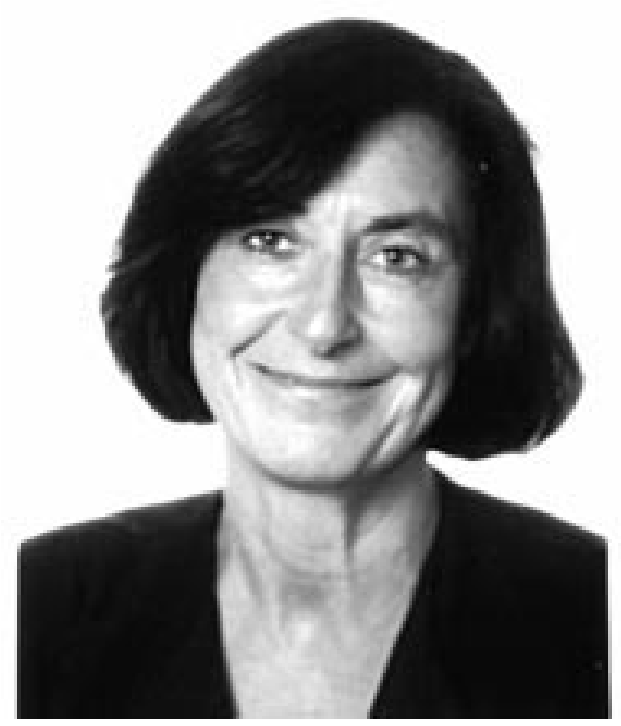

Anne Tursz is French and studied medicine at the University of Paris V. She is a paediatrician and epidemiologist and has a degree in health economics. Her entire career has been devoted to public health, especially child and adolescent health. Her research activities have been directed in particular to the study of the utilisation of health and protective services for children in France and in several developing countries.

For the past 20 years she has carried out epidemiological research on injuries. In 1981-82 she carried out the first population based French study on accidental injuries in childhood, with the double objective of measuring the magnitude of the problem and of evaluating the feasibility of an accident surveillance system. As a result of this work, she represented France on the expert European Committee that developed EH-LASS (European Home and Leisure Accident Surveillance System). At the same time she was, and continues to be, an expert for WHO on the prevention of injuries.

At INSERM (National Institute for Health and Medical Research), where she is Director of Research, she has worked in particular on sports injuries and on the sequelae of childhood injuries. She has published numerous articles, books and book chapters, in French and in English, on several themes, including the epidemiology of injuries during childhood and adolescence, the critical analysis of routine statistics (data from vital statistics and surveillance systems), the prevention of injuries, and adolescent risk behaviours. Her most recent work reviews the organisation and evaluation of the prevention of childhood injuries in France. She has organised several seminars and colloquiums and taught numerous courses in France as well as in developing countries.

At the request of the General Direction of Social Action, she is presently coordinating a study on the long term consequences of child abuse, with a particular interest in identifying pathological conditions linked to unrecognised abuse, and the identification and reliability of relevant sources of information. Specifically, this project includes an analysis of diagnoses of the causes of death among children aged under 1 year and their possible misclassification. 